\title{
Modeling of galvanized lattice steel structures incorporating the effect of joint slip
}

DOI:

10.1016/j.jcsr.2020.106252

\section{Document Version}

Accepted author manuscript

Link to publication record in Manchester Research Explorer

\section{Citation for published version (APA):}

Zhan, Y., Li, B., Wu, Z., Cunningham, L., Wu, G., \& Yang, Y. (2020). Modeling of galvanized lattice steel structures incorporating the effect of joint slip. Journal of Constructional Steel Research, 173, 1-11.

https://doi.org/10.1016/j.jcsr.2020.106252

\section{Published in:}

Journal of Constructional Steel Research

\section{Citing this paper}

Please note that where the full-text provided on Manchester Research Explorer is the Author Accepted Manuscript or Proof version this may differ from the final Published version. If citing, it is advised that you check and use the publisher's definitive version.

\section{General rights}

Copyright and moral rights for the publications made accessible in the Research Explorer are retained by the authors and/or other copyright owners and it is a condition of accessing publications that users recognise and abide by the legal requirements associated with these rights.

\section{Takedown policy}

If you believe that this document breaches copyright please refer to the University of Manchester's Takedown Procedures [http://man.ac.uk/04Y6Bo] or contact uml.scholarlycommunications@manchester.ac.uk providing relevant details, so we can investigate your claim.

\section{OPEN ACCESS}




\title{
Modelling of galvanized lattice steel structures incorporating the effect of joint slip
}

\author{
Yang Zhan, Benben Li*, Zhangjian Wu, Lee S. Cunningham, Gang Wu, Yaqiang Yang
}

\begin{abstract}
The behaviour of galvanized lattice steel structures with joint slip is difficult to model accurately using either theoretical methods or numerical simulations. This paper proposes an accurate and efficient finite element (FE) model for the performance prediction of such structures including the effect of joint slip. In this study, an improved joint-slip model for bolted connections is developed on the basis of experimental results and Ungkurupanian's joint-slip model. Validation of the proposed model is performed utilizing results from full-scale structural testing. Compared with the conventional structural model and the structural model incorporating Ungkurupanian's joint-slip model, the proposed model has the highest accuracy in regard to predicted response. This newly developed model can be readily programmed into existing structural analysis and design software. The proposed model has the potential to improve reliability and safety of lattice structures in practical design.
\end{abstract}

Keywords: Galvanized lattice steel structures; Full-scale structural testing; Joint slip; Finite-element model; Structural response.

\section{Introduction}

Hot-dip galvanizing provides protection from corrosion and aggressive environmental agents and is widely used on a large range of steel structures [1, 2]. Galvanized lattice steel structures, composed of a network of galvanized elements, have considerable spanning capability and inherent corrosion resistance. Due to their structural efficiency (i.e. higher strength-to-weight ratio, ease of construction, fast erection and assembly), such structural forms have been widely used in engineering structures including tower cranes, electricity transmission towers, offshore oil and gas facilities, stadia, long span roofs etc. Where the galvanized members in these structures have bolted connections, as is common in transmission towers, they may exhibit joint slip i.e. a relative displacement of the jointed members when subjected to a shear load [3]. Joint slip occurs because of insufficient frictional resistance between the jointed members. In reality, joint slip is always observed in experiments and can sometimes lead to larger differences in comparison to the structural response prediction from numerical models. Peterson [4], Marjerrison [5] and Rao et al. [6] concluded that the experimental displacements obtained from full-scale transmission towers were approximately 1.3-3 times greater than the numerical results. Al-Bermani and Kitipornchai [7] assessed the behaviour of transmission towers through a proposed nonlinear analytical method which includes the effect of joint flexibility, geometric and material nonlinearities. The work by [7] suggested the large discrepancies between the experimental and analytical results could be attributed to bolt slippage which was not considered in the analyses.

The effect of joint slip in lattice steel structures has been investigated for several decades, and three representative analytical joint-slip models have been proposed by Kitipornchai et al. [8] and 
Ungkurapinan et al. [3, 9]. Specifically, Kitipornchai et al. [8] presented instantaneous and continuous slippage models for typical connections in a tower structure. They reported that bolt slippage had insignificant influence on the ultimate bearing capacity of the tower but substantially affected the displacement of the structure under service loading. However, the two joint-slip models (i.e., instantaneous and continuous slippage models) do not account for the material yielding in connections, which depends on connection type and material properties. Furthermore, the connection performance represented by the two models mentioned above cannot match the experimental results reported by Ungkurapinan [9]. Ungkurapinan et al. [1,9] derived a more accurate joint-slip model through their own experimental investigations. Ahmed et al. [10] reported that joint slip had a considerable effect on the behaviour of a lattice steel tower: under a given service loading, joint slip could either increase the deformation or decrease the ultimate capacity. However, neither material nonlinearity nor joint eccentricity was taken into account in the models and the numerical simulation results were not validated by any tests. Baran et al. [11] evaluated the performance of a bolted splice connection with slippage used in the legs of steel lattice transmission towers by experimental and numerical investigations. They simulated joint slip using contact and target elements available in the FE software ANSYS and found that bolt slip resulted in an increase of deformation while the effect of joint slip on the load carrying capacity is not significant. Subsequently, Jiang et al. [12, 13], Rao et al. [6] and Yaghoobi and Shooshtari [14] investigated the influence of joint slip on the performance of lattice steel towers experimentally and numerically. In Jiang et al. [12], the numerical simulation was conducted incorporating the Ungkurupanian's joint-slip model which was developed for galvanized bolted connections. It should be noted that in the work by [12] the test specimens consisted of mild steel angles. Although Jiang et al. did not provide ultimate load and stiffness predictions from their model, a large difference between the model prediction and experimental results would be expected due to the inappropriate application of the joint-slip model. Jiang et al. [13] established an improved joint-slip model based on Ungkurupanian's joint-slip model. However, one of the key model parameters i.e. deformation due to plasticity, was not provided. It should be noted that only one single linear relationship was used to represent the elastic and slippage regions of the joint in this model, which is unrealistic according to the experimental results from Cruz et al. [15] and the present authors' test results (to be shown later in this paper). The ultimate load and stiffness predictions from the model by [13] were not provided. Rao et al. [6] concluded that joint slippage had significant influence on the displacement of a tower structure and the deformation could be accurately predicted as long as the effect of joint slip was taken into account in a modified model. However, relatively large differences in the stiffness were found between the results obtained from the analytical method and the experiment. Yaghoobi and Shooshtari [14] proposed a joint-slip model for connections in wind turbine lattice towers based on connection test results. However, the equations defining the model had no direct relation to the physical behaviour of the joint. and a detailed validation of the model was not performed [16]. To date, in comparison with full scale testing, no numerical investigation has reported any reliable model that can accurately predict the performance of galvanized lattice steel structures incorporating the effect of joint slip.

In the present paper, a new accurate and efficient finite element (FE) model for predicting the behaviour of galvanized lattice steel structures with joint slip is developed. An improved joint-slip 
model for bolted connections is proposed on the basis of connection test results and Ungkurupanian's joint-slip model [3,9]. A detailed validation of the proposed model is conducted via comparison with the experimental results from a full-scale galvanized lattice steel girder test conducted by the authors. For comparison purposes, the response predictions from the conventional structural model, the Ungkurupanian's joint-slip model and the proposed model are also presented.

In comparison to the aforementioned existing models, the proposed new model captures more realistic load-deformation variation in the slippage stage and combines bearing and plastic stages with a line function to represent connection deformation in order to avoid the determination of the transition point from bearing to plastic stages. In addition to the improved level of accuracy, the model is comparatively straightforward to implement in standard analysis and design codes, thus allowing for ease of adoption in real life design applications.

\section{Experimental investigation}

\section{Connection test}

The connection test was performed for the determination of the relevant parameters to be used in the improved joint-slip model derived by the authors in the following sections. A total of eight specimens (J1-J8) that replicate the connections between the chords and bracing members in a full-scale lattice steel girder were tested. As shown in Figure 1, within the effective test length, the steel plate $(80 \times 15 \mathrm{~mm})$, the angle $(\mathrm{L} 45 \times 5)$, the high-strength bolts (Grade $8.8 \mathrm{M} 16)$ and washers were galvanized to simulate the connections in the girder, while the surfaces of the steel plate and fasteners outside of this length (i.e., griping areas) of the specimens were not galvanized to increase the anchorage effectiveness. All the steel plates and the angles were fabricated from Grade Q345B steel. The experimental setup is shown in Figure 2. Two LVDTs (L1 and L2) were used to measure the relative displacement of the jointed members in the testing region and to determine the anchorage effectiveness, respectively. The corresponding test results will be presented in the following sections.

\section{Full-scale lattice steel girder test}

For the purpose of assessing the performance of the structural models including the joint-slip model proposed by Ungkurupanian et al. [3, 9] and the authors' model respectively, a full-scale galvanized lattice steel girder was tested under a concentrated load. The girder is made of six pairs of chords tapered in sections from bottom to free end, back-to-back crossed diagonal members and diaphragm bracings. The diaphragm and diagonal members have the same angles of $L 45 \times 5$. The length and cross section dimensions of the specimen are $11530 \mathrm{~mm}$ and $1200 \times$ $1067 \mathrm{~mm}$, respectively. The specimen was confined by steel anchorages fixed to the reaction wall and its free end was loaded with an external concentrated force (see Figure 3(c)). The top of the specimen was designed to be stiffer to avoid premature failure during loading. Table 1 and Figure 3(a) show the geometric specification of the steel members in the girder. All members which were made out of Grade Q345B steel were connected by Grade 8.8 M16 bolts. All connections in the specimen were bearing-type bolted and oversized bolt holes were used to produce an erection tolerance of $1.5 \mathrm{~mm}$ according to Lee and Ho [17]. The test setup and the locations of 
measuring devices are indicated in Figures 3 and 4, respectively. The experimental results including the failure mode, ultimate strength, load-deflection relationship and deflections of different points at different percentages of the ultimate load, will be presented in the following sections.

\section{FE modelling}

\section{Improved joint-slip model}

Ungkurapinan and collaborators [3, 9] developed an idealized joint-slip model for typical galvanized single-leg bolted connections through experimental work. As shown in Figure 5, this model can be divided into four regions, that is, elastic stage (Region 1), slippage stage (Region 2), bearing stage (Region, 3) and plastic stage (Region, 4). The values of key points in the joint-slip model were provided when the number of bolts in the connection was no more than 4 . When the number of bolts exceeds 4 , these key values can be calculated according to empirical mathematical expressions. In Ungkurapinan's joint-slip model, the slip load (A, see Figure 5 ) and ultimate load ( $C$, see Figure 5 ) of the bearing-type bolted connection are only governed by the number of bolts in the connection, as given by Eqs. (1) and (2), respectively [3],

$$
A=12.212 n_{b}-4.115
$$

$C=34.6 n_{b}-82.86$

where $n_{b}$ is the number of bolts in the connection. However, the slip load should be dominated by the slip factor of the friction surface, the number of friction surfaces and the bolt preloading force [18]. The ultimate load of a bearing connection, which is governed by either bolts in shear or plates in bearing against the bolts, should be closely related to the mechanical properties of the bolts and/or plates. It is noted that the stiffness of the slippage stage (Region 2) of the Ungkurapinan model is simply set to zero. In fact, the experimental results from Cruz et al. [15] and the present authors' test results (presented later in this paper) confirm that the stiffness during this stage is greater than zero. Meanwhile, the slippages $\left(D_{s}\right.$, see Figure 5$)$ for the three configurations of initial bolt/hole clearance (Figure 6) have three fixed values in this model. Obviously, these values could be dependent on the diameters of bolts and holes. Furthermore, Ungkurapinan's joint-slip model uses the linear expression Eq.(3) to formulate the load $(P)-$ deformation $(D)$ relation in the plastic stage of the joint-slip [3]:

$$
P=\frac{C-B}{R}\left(D-\frac{A}{k_{s 1}}-D_{s}-Q\right)+B \quad \text { for } A / k_{s l}+D_{s}+Q \leq D \leq A / k_{s l}+D_{s}+Q+R
$$

where $A, B, C, D_{s}, Q, R$ and $k_{s 1}$ are the parameters in Ungkurapinan's joint-slip model as shown in Figure 5. The use of an empirical linear relationship to describe Region 4 may lead to inaccuracies in this particular model. Consequently, it can be inferred that Ungkurapinan's joint-slip model may not describe the performance of galvanized bolted connections with joint slip accurately.

An improved joint-slip model for typical galvanized single-leg bolted connections was suggested based on the authors' experimental results and Ungkurapinan's joint-slip model [3, 9], as shown in Figure 7. It is evident that this improved model can be subdivided into three regions: elastic (Region 1), slippage (Region 2) and combined bearing-plastic (Region, 3). Each region is simplified by a linear load-deformation relation. The corresponding values of key points at different regions 
can be determined according to the following equations.

$P_{s 1}=k_{b s} n \mu F_{p}$

The parameter $k_{b s}$ is dependent on the size of the hole.

$k_{b s}=\left\{\begin{array}{l}0.5 \text { (long slotted holes) } \\ 0.7 \text { (over size or slotted holes }) \\ 1.0 \text { (standard holes })\end{array}\right.$

Where $P_{s 1}$ is the slip load at the onset of slippage; $n$ is the number of friction surfaces; $\mu$ is the slip factor and $F_{p}$ is the preloading force on the bolts. The slip load at the end of slippage, $P_{s 2}$, is given by

$P_{s 2}=P_{s 1}+k_{s 2} D_{s}$

in which

$k_{s 2}=0.07 k_{s 1}$

$k_{s 1}=36.3 n_{b}+0.4$

are the stiffnesses of the slippage stage (Region 2 ) and the elastic stage (Region 1), respectively. The extent of slippage during the slippage stage (Region 2 ), $D_{s}$, is taken as

$D_{s}= \begin{cases}0 & (\text { full bearing-Figure } 6(a)) \\ \left(d_{h}-d_{b}\right) / 2 & (\text { normal centered bolt in a hole }- \text { Figure } 6(b)) \\ d_{h}-d_{b} & (\text { maxmiun clearance-Figure } 6(c))\end{cases}$

and $d_{h}$ and $d_{b}$ are the nominal diameters of the hole and bolt respectively. The ultimate load of the connection in the region $3, P_{u}$, should be given by

$$
P_{u}=\operatorname{Minmum}\left(n n_{b} \frac{\pi d_{b}^{2}}{4} f_{v b}, n_{b} d_{b} t_{p} f_{c b}\right)
$$

where $t_{p}$ is the thickness of the thinner connected part; $f_{v b}$ and $f_{c b}$ are the shear strength and the bearing strength of the bolts respectively. The displacements during the combined bearing-plastic stage, $D_{b u}$, and overall displacement of the connection, $D_{u}$, are, respectively, given by

$D_{b u}=-1.7 n_{b}+9.4$

$D_{u}=D_{l}+D_{s}+D_{b u}$

where $D_{l}$ is the displacement in the elastic stage.

In this improved model, a prediction of the slip load at the onset of slippage, $P_{s 1}$, by use of Eq. (4) is recommended by Eurocode 3, Part 1.8 [18]. The ultimate load of the connection, $P_{u}$, is determined from Eq. (10) in accordance with GB50017, the Chinese design code for steel structures [19]. The stiffness of the elastic stage, $k_{s 1}$, and the relative displacement during the combined bearing-plastic stage, $D_{b u}$, determined by Eqs. (8) and (11) respectively, are adopted from the connection experiments performed by Ungkurapinan et al. $[3,9]$ which exhibit the real influence of the number of bolts in the connection $\left(n_{b}\right)$ on the stiffness of the elastic stage $\left(k_{s 1}\right)$ and the relative displacement at the bearing and plastic stage $\left(D_{b u}\right)$. Likewise, Eq. (7) for the 
determination of the stiffness of the slippage stage, $k_{52}$, is developed according to Figure 8 and Table 2 which are the connection test results performed by the authors. The slip load at the end of slippage, $P_{s 2}$, is deduced according to $P_{s 1}, k_{s 2}$ and $D_{s}$ (Eq. (6)). The slippage, $D_{s 1}$, can be evaluated according to the diameters of the holes and bolts (Eq. (9)). A comparison of the $D_{s}$ values obtained from Ungkurapinan's joint-slip model and the improved joint-slip mode is listed in Table 3. It is assumed that the clearance between bolt and hole is approximately proportional to the $D_{s}$ value. Thus, the $D_{s}$ prediction errors from the improved and Ungkurapinan's joint-slip models can be obtained for bolt connections. For the connection with M16 bolts and a bolt hole diameter of $17.5 \mathrm{~mm}$ tested in this paper, it is clear that Ungkurapinan's joint-slip model overestimates the $D_{s}$ by approximately $9.0 \%$, while the improved joint-slip model underestimates the $D_{s}$ by approximately $3.8 \%$ which is less than half of the corresponding prediction error from Ungkurapinan's joint-slip model. Similarly, the prediction error of Ungkurapinan's joint-slip model for $D_{s}$ is approximately $45.5 \%$ while the error decreases to approximately $3.8 \%$ for the improved joint-slip model with $\mathrm{M} 27$ bolts and a bolt hole diameter of $30 \mathrm{~mm}$. Although both models underestimate the slippage for larger diameter bolt / bolt hole, the fixed $D_{s}$ value in Ungkurapinan's joint-slip model can lead to much larger error and unstable prediction. Eq. (9) for $D_{s}$ in the improved joint-slip model has better prediction and much less error for different diameters of bolts and holes in connections.

Generally, the failure mode of lattice steel structures tends to be buckling of chords or web members, the premature failure of connections is aimed at being avoided in structural design. For the following lattice girder test (see the section on Model validation), the axial force of the tensile or compressive web members is approximately $55 \mathrm{kN}$ at the failure of the structure. According to the connection test results (Figure 8), the connection joints are clearly in the bearing phase i.e. the connection has not yet entered the plastic stage. However, determining a clear transition turning point from bearing to plastic stages in the test curves of Figure 8 is difficult. It is hence proposed to use a straight line to represent the bearing and plastic stages of the connection collectively as a combined bearing-plastic stage in the improved joint-slip model when considering the convenience and the requirements of engineering design. Obviously, such an improved model may underestimate the stiffness of connection in bearing and plastic stages slightly. The difference and error caused by such a model simplification will be further assessed and compared in the section on Model validation.

The performance of the improved joint-slip model is evaluated in accordance with the connection test results. Table 4 presents the experimental results and the predictions from the improved joint-slip model. It is evident that the improved joint-slip model underestimated the slip loads $\left(P_{s 1}\right.$ and $\left.P_{s 2}\right)$ and the ultimate load of the connection $\left(P_{u}\right)$. The corresponding displacement parameters $\left(D_{1}, D_{s}, D_{u}\right)$, except for the extent of slippage $\left(D_{s}\right)$, were overestimated. Specifically, the improved joint-slip model gave an excellent prediction for $P_{s 1}, P_{s 2}, P_{u}$ and $D_{s}$, with an underestimation of only $4.8 \%, 7.1 \%, 9.7 \%$ and $3.5 \%$, respectively, in comparison with the corresponding average experimental values. The displacement parameters, $D_{l}, D_{b u}$ and $D_{u}$ predicted by the improved joint-slip model were $12.4 \%, 14.8 \%$ and $12.4 \%$ higher, than the corresponding experimental values. It is seen that the predictions of the improved joint-slip model were in reasonable agreement with the corresponding experimental results thus 
indicating the validity of Eqs. (4)-(12). Here the normal configuration of the bolt centered in a hole (Figure 6 (b)), considered to be more common than the other two bolt configurations [12], was adopted in the current improved joint-slip model. Compared with Ungkurapinan's joint-slip model, the improved model adopts a symmetric tensile and compressive loading-slippage relation with non-zero stiffness $\left(k_{s 2}\right)$ during the slippage stage $\left(D_{s}\right)$. The slip load at the onset of slippage $\left(P_{s 1}\right)$ and ultimate capacity $\left(P_{u}\right)$ are determined from the formulae presented in Eqs. (4) and $(10)$ based on the previously mentioned national codes $[18,19]$. The more accurate and intuitive constitutive description infers that the improved joint-slip model may have better applicability and versatility.

\section{FE modelling}

To check the accuracy of the proposed model in simulating the galvanized lattice steel girder test previously described, a three-dimensional FE model was developed using ANSYS finite element software [20]. Because the nonlinear response of a lattice structure cannot be obtained from a truss model [21, 22], the lattice girder was simulated using spatial frame elements. For the purpose of comparison, three numerical simulation results based on the proposed model (Model $P)$, the structural model including the Ungkurapinan's joint-slip model (Model $U$ ) and the conventional structural model (Model C), were presented.

In Model P, BEAM188, a 3-D 2-node beam element, was adopted to model all steel members (i.e., chords and bracing members) in the lattice girder. The BEAM188 element has seven degrees of freedom at each node, while warping, one of these degrees of freedom, was neglected. The lap-splice connections between the chords were assumed to be rigid according to experimental results, therefore the chords were connected by one node (Figure 9(a)). For the connections at the middle of the back-to-back crossed diagonal members, the nodes at the intersection points were coupled with six degrees of freedom (Figure 9(b)). In order to capture the effect of joint slip observed in the experimental test, the COMBIN39 nonlinear spring element was adopted to simulate the single-leg bolted connections between the chords and bracing members (Figure 9(c)). This element can be used to simulate nonlinear joint-slip behaviour in single-leg bolted connections when an appropriate loading-slippage relationship is adopted. The normal configuration of the bolt centered in the bolt hole (Figure 6(b)) was used in the proposed improved joint-slip model. The improved joint-slip model (Figure 7) was adopted as the loading-slippage relationship in the COMBIN39 element, this relationship significantly influences the prediction. Figure 10 shows a schematic diagram of the FE model (Model P) for the lattice girder. The red arrows at the bottom and free end of the lattice girder denote the directions of inertial force and concentrated load, respectively. Model $U$ was generally identical to Model $P$, except that Ungkurapinan's joint-slip model (Figure 5) was used as the load-slippage relationship in the COMBIN39 element. Similarly, Model C was generally the same as Model P, except that all connections in the lattice column were assumed to be rigid.

For all three FE simulations, geometric nonlinearity was induced by the NLGEOM command in ANSYS. The steel members were assumed to be isotropic. The elastoplastic bilinear material behaviour (Figure 11), which was plotted according to the results of coupon tests listed in Table 5, was adopted to define the material constitutive model of the steel members. The load point of 
the web member ( $L 45 \times 5$ ) was specified to simulate the load eccentricity in the web member, as shown in Figure 12, i.e. the load eccentricity of the bracings was triggered by modifying the location of the centroid. Thus, the geometric and material nonlinearities and the load eccentricity were all taken into consideration. The girder to be simulated numerically was connected to the reaction wall by rigid links. Additionally, yielding was assessed via the von Mises criterion. The Newton-Raphson method was selected to accelerate the numerical convergence of the solutions for the nonlinear problem. The load increments were applied in 20-35 steps until failure was reached.

\section{Model validation}

For the galvanized lattice steel girder subjected to a concentrated load at its free end, the numerical FE simulation load versus deflection response at various locations based on Models $\mathrm{P}$, $\mathrm{U}$ and $\mathrm{C}$, together with that of the experimental result, are shown in Figures 13 and 14.

\section{Deflection response}

Figure 13 gives the numerical and experimental deflections of different points on the specimen at different percentages of the ultimate load. It is clear that the prediction of Model $\mathrm{C}$ does not match the test results and the corresponding prediction error increases with the increment of the applied load. For example, at $30 \%$ of the ultimate load $(47.3 \mathrm{kN})$, which is less than the slippage load of the structure $(50 \mathrm{kN})$, the deflection at point $\mathrm{G}$ (see Figure 4 ) predicted by Model $\mathrm{C}$ is $43.1 \%$ lower than the corresponding experimental value (Figure 13 (a)). Subsequently, the prediction error increases sharply after the applied load exceeds the threshold slippage load of the specimen. The deflection of point $\mathrm{G}$ at $50 \%$ of the ultimate load $(78.8 \mathrm{kN})$ obtained from Model $\mathrm{C}$ is $63.7 \%$ less than the corresponding experimental result. This means the error has an increase of approximately $21 \%$ compared with that at $30 \%$ of the ultimate load. When the applied load increases from $70 \%$ to $90 \%$ of the ultimate loads, the corresponding deflection error at point $\mathrm{G}$ increases slightly from $65.7 \%$ to $66.1 \%$. This greater prediction error of Model C could be mainly attributed to (1) the over prediction of the stiffness of the girder that was assumed to be rigid and (2) the degradation of the test specimen's stiffness that is induced by the slippage of bolts after the applied load exceeds the slippage threshold load of the girder.

Unlike Model C, Models $\mathrm{U}$ and $\mathrm{P}$ display better prediction performance, as shown in Figure 13. Of the two models, Model $\mathrm{P}$ exhibits higher accuracy in predicting the deflection response of the focused structure. At 30\% of the ultimate load, the predictions from Models $U$ and $P$ are both lower than the test results. The deflections of point $G$ predicted by Models $U$ and $P$ are $19.3 \%$ and $14.8 \%$ lower, respectively, than the corresponding experimental value. That is, when the applied load is less than the slippage load of the structure, the errors from the prediction of these two models are both less than half of that from Model C (43.1\%). The main reason for the deflection underestimation of Models $U$ and $P$ could be due to the fact that the influence of residual stress and geometric imperfection in the test girder is not taken into account. Note that the inevitable residual stress (caused by assembling and manufacturing of steel structural members) could result in a loss of stiffness of structure [23-27]. When the applied load is larger than the slippage force of the specimen, i.e., at $50 \%, 70 \%$, and $90 \%$ of the ultimate loads, the 
predictions from both Models $\mathrm{U}$ and $\mathrm{P}$ are higher than the experimental results, and the errors from the predictions of the two models gradually reduce with increasing load. More specifically, at the loads of $50 \%, 70 \%$ and $90 \%$ of the ultimate load, the errors from the prediction of Model $U$ for the deflection of point $\mathrm{G}$ are $35.2 \%, 21.1 \%$ and $20.5 \%$ respectively, while Model $\mathrm{P}$ gives the corresponding prediction errors of $19.3 \%, 11.6 \%$ and $10.1 \%$ respectively. Compared with the error from Model C (66.1\%), the corresponding errors based on the predictions of Models $U$ and $\mathrm{P}$ at $90 \%$ of the ultimate load reduce by $45.6 \%$ and $56 \%$ respectively.

The main reason for the deflection overestimation of Models $U$ and $P$ could be due to the implementation of the two joint-slip models (Figures 5 and 7). Since both models used the corresponding load-slippage relationships as parametric inputs in COMBIN39 elements for the structural analysis, it implies that all the joints between the chords and bracing members could undergo the entire slippage process from the initial to the ultimate states. However, not every connection of the specimen can experience the entire slippage process during the experiment; some joints could not slip to the ultimate state because of the existing small moments along the transverse axes perpendicular to the longitudinal axis of the bracing member. A zero-slope horizontal line in the slippage stage of Ungkurapinan's joint-slip model (Model $U$ ) and a linear relationship for the combined bearing-plastic stage in the improved joint-slip model (Model P) are respectively adopted to represent part of the joint-slip curve in these models. These model simplifications could lead to lower stiffness prediction in the corresponding stages (note: not for the initial elastic stage) compared with the real test result. The results also indicate that the influence of the joint-slip model may override that of residual stress and geometric imperfection when loading exceeds a value of more than $30 \%$ (but less than $50 \%$ ) of the ultimate load. Moreover, joint slip was observed with the applied load ranging from $50 \mathrm{kN}$ to $80 \mathrm{kN}$ approximately during the test (Figure 14). These facts indicate that structural deflection mainly occurred after $30 \%$ of the ultimate loads. This explains why the errors of Models $U$ and $P$ progressively decreased as the applied load increased from $50 \%$ to $70 \%$ and $90 \%$ of the ultimate loads. Furthermore, the stiffness of the connection in the slippage stage of Model P is small but greater than zero (Region 2), while Ungkurapinan's joint-slip model simply sets it to zero. This could be a reason that Model $U$ gives a larger deflection prediction than that of Model P. Due to the similarity of the structural deformation, the deflections of the other six points of $\mathrm{H}, \mathrm{I}, \mathrm{J}, \mathrm{K}, \mathrm{L}$, M (Figure 4) are not presented in Figure 13.

\section{Load-deflection relationship and stiffness response}

Figure 14 compares the model predictions and the experimental results of the applied load versus the deflection on top of the specimen's free end. The deflection curve predicted by Model $\mathrm{C}$ is linear up to the ultimate load and approximately coincides with the test results when the applied load is less than $20 \mathrm{kN}$. However, with the load in excess of $20 \mathrm{kN}$, the deflection curve from Model $\mathrm{C}$ deviates from the experimental curve. The deflection error based on the prediction of Model $\mathrm{C}$ increases with the increment of the applied load. It is observed that the threshold slippage load of the specimen is $50 \mathrm{kN}$ experimentally, and the joint slip process is nearly completed after the applied load exceeds $80 \mathrm{kN}$. Table 6 presents the stiffness values of the specimen obtained from the experimental results. The error of the stiffness drastically increases from approximately $23 \%$ to $166 \%$ with the load changing from $20 \mathrm{kN}$ to $80 \mathrm{kN}$ in Model C. This 
could be attributed primarily to the overestimation of the rigidity of the specimen by Model C because this model does not consider the effect of joint slip. When the applied load reaches $80 \mathrm{kN}$, the stiffness of the specimen is approximately $42 \%$ lower than that of the specimen under the applied load of 50kN. At the ultimate load, the model prediction error can be as high as $189 \%$ approximately.

Models $\mathrm{U}$ and $\mathrm{P}$ agree with the experimental results very well when the applied load is less than $20 \mathrm{kN}$. However, this agreement is lost progressively with the increase of the applied load, especially for the predictions of Model $U$. When the applied load reaches $20 \mathrm{kN}$, the stiffnesses predicted by Models $\mathrm{U}$ and $\mathrm{P}$ are larger, approximately $16 \%$ and $14 \%$ respectively, than that obtained from the experimental test (see Table 6). As the load increases to $50 \mathrm{kN}$, the stiffness from Model $U$ is approximately $37 \%$ lower than that measured in the test. This could be due to the fact that the slip load of the specimen at the onset of slippage predicted by Model $\mathrm{U}(48 \mathrm{kN})$ is slightly lower than that measured in the experiment $(50 \mathrm{kN})$, see Table 7. Meanwhile, the slip load of the specimen at the end of slippage predicted by Model $U(52 \mathrm{kN})$ is much less than that obtained from the test $(80 \mathrm{kN})$, as shown in Table 7. Moreover, the average stiffness of the slippage stage of the specimen predicted by Model $U(0.037 \mathrm{kN} / \mathrm{mm})$ is approximately one tenth of that measured in the test $(0.353 \mathrm{kN} / \mathrm{mm})$, see Figure 14 . Compared with the prediction error of Model $\mathrm{U}$, the error of Model P decreases to approximately $5 \%$ as the load increases to $50 \mathrm{kN}$. This could be attributed to the relatively accurate loading-joint slippage for the structural behaviour prediction by Model P. As the applied load increases to the ultimate load, the stiffness obtained from Model $\mathrm{U}$ is approximately $23 \%$ lower than that measured in the test. The corresponding stiffness error from the prediction of Model $P$ reduces to $14 \%$ approximately. Clearly, the predictive accuracy of Model $\mathrm{P}$ is better than that of Model $\mathrm{U}$ in regards to the behaviour of the focused structure. Model P exhibits the most accurate predictions compared with the other two models mentioned.

Table 7 summarizes the model predictions and test results for the specimen. It is clear that all three models can predict the ultimate load of the specimen. A big difference is observed among their capabilities in predicting the deflection of the specimen. The deflection predicted by Model $\mathrm{C}$ at the top of the specimen is only one third of the experimental value approximately. Model $\mathrm{U}$ overestimates the deflection of the specimen with an error of approximately $25 \%$, while the error from the prediction with Model P is only $12 \%$.

\section{Failure mode}

A graphical comparison between the test and predicted failure modes is given in Figure 15. The failure modes of the girder predicted by Models $\mathrm{C}, \mathrm{U}$ and $\mathrm{P}$ are the same, as shown in Figure 15(b). The numerical failure mode, dominated by the buckling of the compressive web members on both sides of the first two panels near the free loaded end, is evidently supported by the experimental test. This remarkable similarity between the experimental and numerical failure modes indicates that Models $\mathrm{C}, \mathrm{U}$ and $\mathrm{P}$ can all accurately predict the failure mode of lattice steel structures with joint slip. The influence of joint slippage on the ultimate bearing capacity and the failure mode is not significant when the lattice structure is subjected to concentrated loading. 
The conventional structural model (Model C) which treats all the joints in the specimen as rigid connections substantially underestimates the deflection and considerably over-predicts the stiffness of the focused structure. Therefore, the conventional structural model cannot be used to predict the behaviour of galvanized lattice steel structures with joint slip, even though it can predict the ultimate load and failure mode correctly. Meanwhile, Model $\mathrm{U}$ considering the joint slippage by Ungkurapinan's joint-slip model should be used cautiously to estimate the performance of galvanized lattice steel structures with joint slip, since the prediction errors of Model $U$ could be as large as $20 \%$ or greater in deflection and stiffness in comparison with the experimental tests. The proposed model (Model P) taking the effect of joint slip into account through the improved joint-slip model has more accurate deflection and stiffness predictions (both deflection and stiffness prediction errors are less than 15\%) and stronger applicability and versatility compared with Model U.

\section{Summary and conclusions}

This paper proposed an accurate and efficient FE model for predicting the performance of galvanized lattice steel structures including the effect of joint slip, in which an improved joint-slip model was developed to simulate slippage in the connections. The proposed model was validated and compared with the conventional structural model and a structural model including Ungkurapinan's joint-slip model. Of the results of this investigation, the following issues should be emphasized:

1. Joint slippage considerably increases the deflection and substantially decreases the stiffness of galvanized lattice steel structures. Its influence on the ultimate bearing capacity and the failure mode is insignificant when the lattice structure is subjected to concentrated lateral loading.

2. The conventional structural model which underestimates the deflection and over-predicts the stiffness of the structure considerably cannot be used to predict the performance of galvanized lattice steel structures with joint slip, although it can correctly predict the ultimate load and failure mode.

3. Model U incorporating the joint slippage model proposed by Ungkurapinan should be used with caution to estimate the behaviour of the focused structure type in view of the significant prediction errors observed in the case studies presented here (deflection and stiffness prediction errors $>20 \%$ ).

4. The proposed model taking account of joint slip through the improved joint-slip model can accurately predict the responses of the focused structure. This proposed model can be readily programmed into existing structural analysis/design software and has the potential to improve design of new galvanized lattice steel structures with bolted connections and assessment of existing structures of this type.

\section{Acknowledgments}

This research was financially supported by the National Natural Science Foundation of China (Grant Nos: 51708259, 51525801 and 51808265), the Royal Society of the UK (Grant No: 
R122363) and the Scientific Research Foundation of Nanjing Institute of Technology (Grant No: YKJ201925). Support from these sources is gratefully acknowledged.

\section{References}

[1] F. Berto, O. Fergain, Fatigue behaviour of welded structural steel subjected to hot-dip galvanization process, Int. J. Fatigue. 101 (2017) 439-447.

[2] F. Berto, F. Mutignani, M. Tisalvi, Notch effect on the fatigue behavior of a hot-dip galvanized structural steel, Strength Mater. 47 (5) (2003) 719-727.

[3] N. Ungkurapinan, S.R.De S. Chandraleerthy, R.K.N.D. Rajapakse, S.B. Yue, Joint slip in steel electric transmission towers, Eng. Struct. 25 (6) (2003) 779-788.

[4] W.O. Peterson, Design of EHV steel tower transmission lines, J. Power Div. 88 (1) (1962) 39-66.

[5] M. Marjerrison, Electric transmission tower design, J. Power Div. 94 (1) (1968) 1-24.

[6] N.P. Rao, G.M.S. Knight, N. Lakshmanan, N.R. Iyer, Effect of bolt slip on tower deformation, Pract. Period. Struct. Des. Constr. 17 (2) (2012) 65-73.

[7] F.G.A. Al-Bermani, S. Kitipornchai, Nonlinear analysis of transmission towers, Eng. Struct. 14 (3) (1992) 139-151.

[8] S. Kitipornchai, F.G.A. Al-Bermani, A.H. Peyrot, Effect of bolt slippage on ultimate behavior of lattice structures, J. Struct. Eng. 120 (8) (1994) 2281-2287.

[9] N. Ungkurapinan, A study of joint slip in galvanized bolted angle connections, M.S. thesis, Univ. of Manitoba, Winnipeg, Canada, 2000.

[10] K.I.E. Ahmed, R.K.N.D. Rajapakse, M.S. Gadala, Influence of bolted-joint slippage on the response of transmission towers subjected to frost-heave, Adv. Struct. Eng. 12 (1) (2009) 117.

[11] E. Baran, T. Akis, G. Sen, A. Draisawi, Experimental and numerical analysis of a bolted connection in steel transmission towers, J. Constr. Steel Res. 121 (2016) 253-260.

[12] W.Q. Jiang, Z.Q. Wang, G. McClure, G.L. Wang, J.D. Geng, Accurate modeling of joint effects in lattice transmission towers, Eng. Struct. 33 (2011) 1817-1827.

[13] W.Q. Jiang, Y.P. Liu, S.L. Chan, Z.Q. Wang, Direct analysis of an ultrahigh-voltage lattice transmission tower considering joint effects, J. Struct. Eng. 143 (5) (2017) 04017009.

[14] S. Yaghoobi, A. Shooshtari, Joint slip formulation based on experimental results in wind turbine lattice towers, J. Struct. Eng. 144 (6) (2018) 04018058.

[15] A. Cruz, R. Simões, R. Alves, Slip factor in slip resistant joints with high strength steel, J. Constr. Steel. Res. 70 (2012) 280-288.

[16] Y. Zhan, B.B. Li, Discussion of "Joint slip formulation based on experimental results in wind turbine lattice towers" by Saleh Yaghoobi and Ahmad Shooshtari, J. Struct. Eng. 146 (7) (2018) 07020003.

[17] Y.L. Lee, H.C. Ho, Chapter 12-Design and analysis of metric bolted joints: VDI guideline and finite element analysis, Metal fatigue analysis handbook, Butterworth-Heinemann, New York, (2012) $461-513$.

[18] CEN, EN 1993-1-8: Eurocode 3: Design of Steel Structures-Part 1-8: design of joints, European Committee for Standardization, Brussels, 2005.

[19] GB50017-2017: Code for design of steel structures, Beijing, 2017.

[20] ANSYS, ANSYS user's manual, release 10.0, Canonsburg, Pennsylvania: ANSYS Inc., 2009.

[21] P.S. Lee, G. McClure, Elastoplastic large deformation analysis of a lattice tower structure and 
comparison with full-scale tests, J. Constr. Steel. Res. 63 (5) (2007) 709-717.

[22] R.C. Battista, R.S. Rodrigues, M.S. Pfeil, Dynamic behavior and stability of transmission line towers under wind forces, J. Wind. Eng. Ind. Aerodyn. 91 (8) (2003) 1051-1067.

[23] R.B. Cruise, L. Gardner, Residual stress analysis of structural stainless steel sections, J. Constr. Steel Res. 64 (3) (2008) 352-366.

[24] J. Jiang, C.K. Lee, S.P. Chiew, Residual stress and stress concentration effect of high strength steel built-up box T-joints, J. Constr. Steel Res. 105 (2015) 164-173.

[25] S. Shayan, K.J.R. Rasmussen, H. Zhang, On the modelling of initial geometric imperfections of steel frames in advanced analysis, J. Constr. Steel Res. 98 (2014) 167-177.

[26] M.S. Hassan, S. Salawdeh, J. Goggins, Determination of geometrical imperfection models in finite element analysis of structural steel hollow sections under cyclic axial loading, J. Constr. Steel Res. 141 (2018) 189-203.

[27] T. Ma, L. Xu, Effects of column imperfections on capacity of steel frames in variable loading, J. Constr. Steel Res. 165 (2020) 105819.

[28] G.L. Kulak, J.W. Fisher, J.H. Struik. Guide to design criteria for bolted and rivet joints. Second Edition. New York: John Wiley \& Sons; 1987. 
Table 1

Specifications of the steel members used in the experiments

\begin{tabular}{cc}
\hline Member & Cross section $(\mathrm{mm})$ \\
\hline C1 2 & $\mathrm{~L} 140 \times 12$ \\
C2 3 & $\mathrm{~L} 125 \times 10$ \\
Diagonal and diaphragm member & $\mathrm{L} 100 \times 10$ \\
\hline
\end{tabular}

Note: C1, C2 and C3 are indicated in Fig. 3(a).

Table 2

Experimental results for $k_{s 1}$ and $k_{s 2}$

\begin{tabular}{lccc}
\hline Specimen & $k_{s 1}(\mathrm{kN} / \mathrm{mm})$ & $k_{s 2}(\mathrm{kN} / \mathrm{mm})$ & $k_{s 2} / k_{s 1}$ \\
\hline $\mathrm{J} 1$ & 83.78 & 4.19 & 0.05 \\
$\mathrm{~J} 2$ & 98.00 & 5.88 & 0.06 \\
$\mathrm{~J} 3$ & 71.67 & 7.17 & 0.1 \\
$\mathrm{~J} 4$ & 77.65 & 6.21 & 0.08 \\
$\mathrm{~J} 5$ & 90.65 & 6.35 & 0.07 \\
$\mathrm{~J} 6$ & 82.41 & 7.42 & 0.09 \\
$\mathrm{~J} 7$ & 94.00 & 5.64 & 0.06 \\
$\mathrm{~J} 8$ & 101.53 & 5.08 & 0.05 \\
Average & -- & -- & 0.07 \\
\hline
\end{tabular}

Table 3

A comparison of the $D_{s}$ values obtained from Ungkurapinan's joint-slip model and the improved joint-slip model

\begin{tabular}{|c|c|c|c|c|c|}
\hline \multirow{2}{*}{ Bolt } & \multirow{2}{*}{$\begin{array}{c}\text { Experimental } \\
\text { Test } \\
\text { Result }\end{array}$} & \multicolumn{2}{|c|}{ Ungkurapinan's model } & \multicolumn{2}{|c|}{ Improved model } \\
\hline & & Prediction & Error (\%) & Prediction & Error (\%) \\
\hline $\operatorname{M16}\left(d_{b}=16 \mathrm{~mm}, d_{h}=17.5 \mathrm{~mm}\right)$ & 0.78 & 0.85 & 9.0 & 0.75 & -3.8 \\
\hline$M 27\left(d_{b}=27 \mathrm{~mm}, d_{h}=30 \mathrm{~mm}\right)$ & 1.56 & 0.85 & -45.5 & 1.5 & -3.8 \\
\hline
\end{tabular}

Note: Test $=D_{s}$ value from connection experimental test; $d_{\mathrm{b}}$ and $d_{\mathrm{h}}$ are the nominal diameters of the bolt and bolt hole, respectively. The prediction values are determined according to the normal bolt/hole configuration in Figure 6(b).

Error $=(X$-Test $) /$ Test, in which $X=$ a prediction from Ungkurapinan's joint-slip model or the improved joint-slip model. 
Table 4

Experimental results and the predictions from the improved joint-slip model

\begin{tabular}{lccccccc}
\hline Specimen & $\mathrm{P}_{\mathrm{s} 1}(\mathrm{kN})$ & $\mathrm{P}_{\mathrm{s} 2}(\mathrm{kN})$ & $\mathrm{P}_{\mathrm{u}}(\mathrm{kN})$ & $\mathrm{D}_{1}(\mathrm{~mm})$ & $\mathrm{D}_{\mathrm{s}}(\mathrm{mm})$ & $\mathrm{D}_{\text {bu }}(\mathrm{mm})$ & $\mathrm{D}_{\mathrm{u}}(\mathrm{mm})$ \\
\hline $\mathrm{J} 1$ & 19.27 & 23.49 & 83.95 & 0.23 & 1.01 & 5.47 & 6.71 \\
$\mathrm{~J} 2$ & 17.64 & 21.37 & 76.10 & 0.18 & 0.63 & 4.37 & 5.18 \\
$\mathrm{~J} 3$ & 19.35 & 25.18 & 91.81 & 0.27 & 0.81 & 6.32 & 7.40 \\
$\mathrm{~J} 4$ & 15.53 & 20.97 & 88.02 & 0.20 & 0.88 & 5.86 & 6.94 \\
$\mathrm{~J} 5$ & 15.41 & 19.33 & 76.85 & 0.17 & 0.62 & 4.55 & 5.34 \\
$\mathrm{~J} 6$ & 18.13 & 22.41 & 85.58 & 0.22 & 0.58 & 5.39 & 6.19 \\
$\mathrm{~J} 7$ & 17.86 & 22.85 & 82.86 & 0.19 & 0.88 & 5.11 & 6.18 \\
J8 & 17.26 & 21.37 & 81.27 & 0.17 & 0.81 & 4.76 & 5.74 \\
Average & 17.56 & 22.12 & 83.31 & 0.20 & 0.78 & 5.23 & 6.21 \\
Prediction & 16.72 & 20.55 & 75.20 & 0.23 & 0.75 & 6.00 & 6.98 \\
Error (\%) & -4.76 & -7.10 & -9.73 & 12.41 & -3.54 & 14.75 & 12.38 \\
\hline
\end{tabular}

Note: Error $=($ Prediction-Average) $/$ Average.

In the determination of predictions, the parameters of the bolt preloading force $\left(F_{p}\right)$ and the slip factor $(\mu)$ were $88 \mathrm{kN}$ and 0.19 , respectively, according to Eurocode 3, Part 1.8 [18] and Kulak et al. [28].

Table 5

Mechanical properties of the material

\begin{tabular}{lcccc}
\hline Members & Elastic modulus & Yield strength & Tensile strength & Ultimate strain \\
& $E(\mathrm{GPa})$ & $F_{y}(\mathrm{MPa})$ & $F_{u}(\mathrm{MPa})$ & $\varepsilon_{u}(\%)$ \\
\hline Chord & 223.7 & 294.3 & 553.7 & 30.6 \\
Diagonal and diaphragm & 206.3 & 318 & 459 & 22.8 \\
\hline
\end{tabular}

Table 6

Comparison of the stiffness values of the girder obtained from the model predictions and experimental results

\begin{tabular}{|c|c|c|c|c|c|c|c|}
\hline \multirow{3}{*}{$\begin{array}{l}\text { Applied load } \\
(\mathrm{kN})\end{array}$} & \multicolumn{7}{|c|}{ Stiffness (kN/mm) } \\
\hline & \multirow{2}{*}{$\begin{array}{c}\text { Test } \\
\text { Result }\end{array}$} & \multicolumn{2}{|c|}{ Model C } & \multicolumn{2}{|c|}{ Model U } & \multicolumn{2}{|c|}{ Model P } \\
\hline & & Result & Error (\%) & Result & Error (\%) & Result & Error (\%) \\
\hline 20 & 1.238 & 1.524 & 23.1 & 1.432 & 15.7 & 1.413 & 14.1 \\
\hline 50 & 0.997 & 1.530 & 53.5 & 0.632 & -36.6 & 0.948 & -4.9 \\
\hline 80 & 0.575 & 1.530 & 166.1 & 0.425 & -26.1 & 0.481 & -16.3 \\
\hline 110 & 0.535 & 1.523 & 184.7 & 0.435 & -18.7 & 0.480 & -10.3 \\
\hline 140 & 0.522 & 1.517 & 190.6 & 0.435 & -16.7 & 0.474 & -9.2 \\
\hline Ultimate load & 0.525 & 1.515 & 188.6 & 0.406 & -22.7 & 0.452 & -13.9 \\
\hline
\end{tabular}

Note: Stiffness is defined as the ratio of the applied load to the corresponding deflection at the loading point.

Error $=(\mathrm{X}$-Test $) /$ Test, in which $\mathrm{X}=$ a prediction from Models $\mathrm{C}, \mathrm{U}$ or $\mathrm{P}$. 
Table 7

Summary of the model predictions and experimental results

\begin{tabular}{|c|c|c|c|c|c|c|c|}
\hline \multirow[t]{2}{*}{ Items } & \multirow{2}{*}{$\frac{\text { Test }}{\text { Result }}$} & \multicolumn{2}{|c|}{ Model C } & \multicolumn{2}{|c|}{ Model U } & \multicolumn{2}{|c|}{ Model P } \\
\hline & & Result & Error (\%) & Result & Error (\%) & Result & Error (\%) \\
\hline$P_{\text {sis }}(\mathrm{kN})$ & 50.0 & -- & -- & 48.2 & -3.6 & 50.6 & 1.2 \\
\hline$P_{s 2 s}(\mathrm{kN})$ & 80.0 & -- & -- & 51.5 & -35.6 & 63.7 & -20.4 \\
\hline$P_{u s}(\mathrm{kN})$ & 157.5 & 155.0 & -1.6 & 155.0 & -1.6 & 155.0 & -1.6 \\
\hline$D_{u s}(\mathrm{~mm})$ & 306.0 & 102.4 & -66.5 & 382.0 & 24.8 & 343.1 & 12.1 \\
\hline
\end{tabular}

Note: $P_{s 1 s}=$ the slip load of the structure at onset of slippage; $P_{s 2 s}=$ the slip load of the structure at the end of slippage; $P_{u s}=$ the ultimate load of the structure; $D_{u s}=$ the ultimate deflection on top of the structure.

Error $=(\mathrm{X}$-Test $) /$ Test, in which $\mathrm{X}=$ a prediction from Models $\mathrm{C}, \mathrm{U}$ or $\mathrm{P}$.

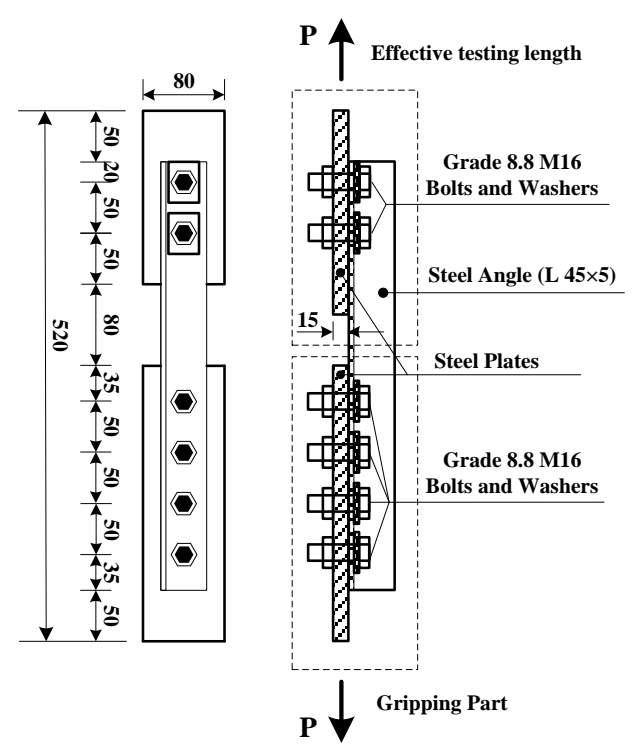

Fig. 1. Detailed view of connection configuration (units in $\mathrm{mm}, \mathrm{P}=\mathrm{load}$ )
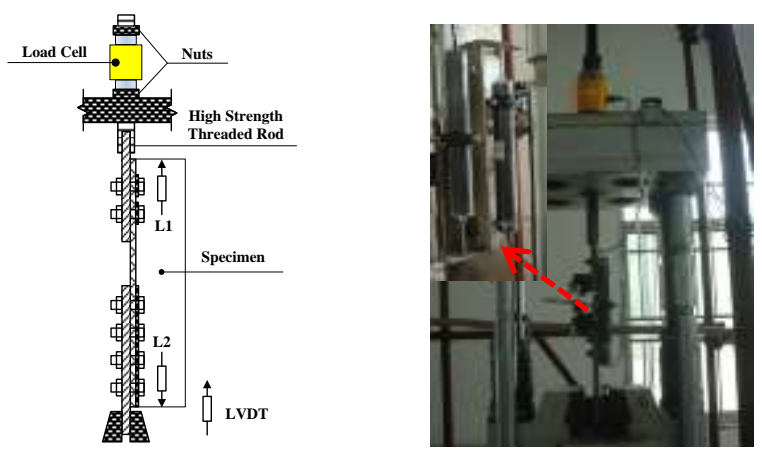

$\begin{array}{ll}\text { (a) schematic view } & \text { (b) general view of experimental setup }\end{array}$

Fig. 2. Connection tests: experimental setup 


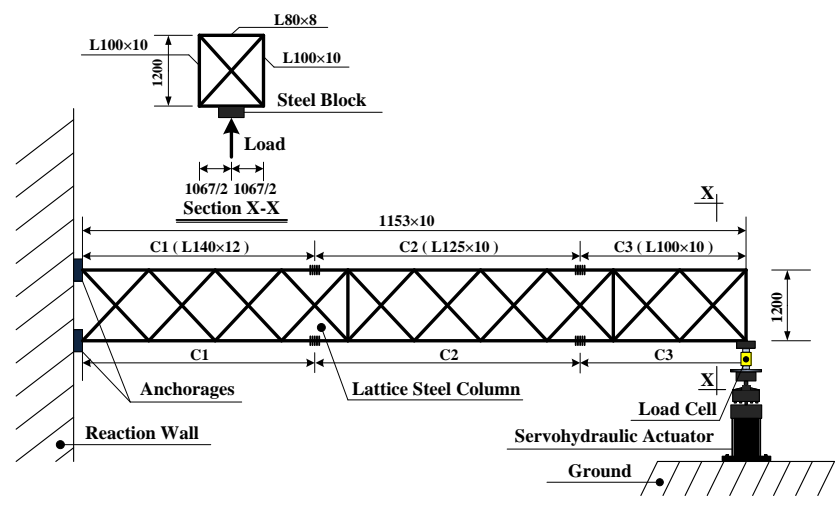

(a) Schematic elevation (units given in $\mathrm{mm}$ )

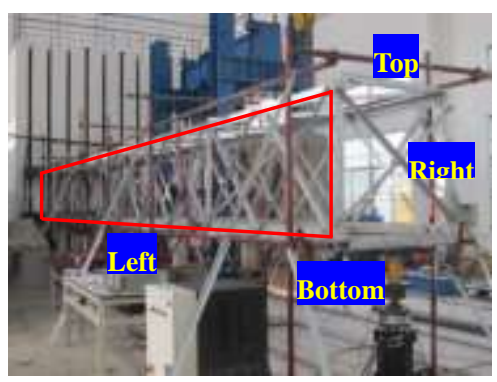

(b) General view of the test arrangement

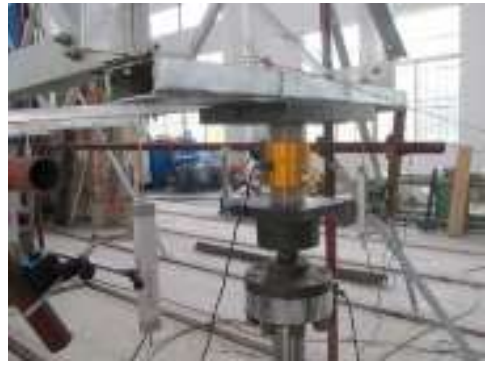

(c) Loading configuration

Fig. 3. Lattice girder: test set-up and specimen general arrangement

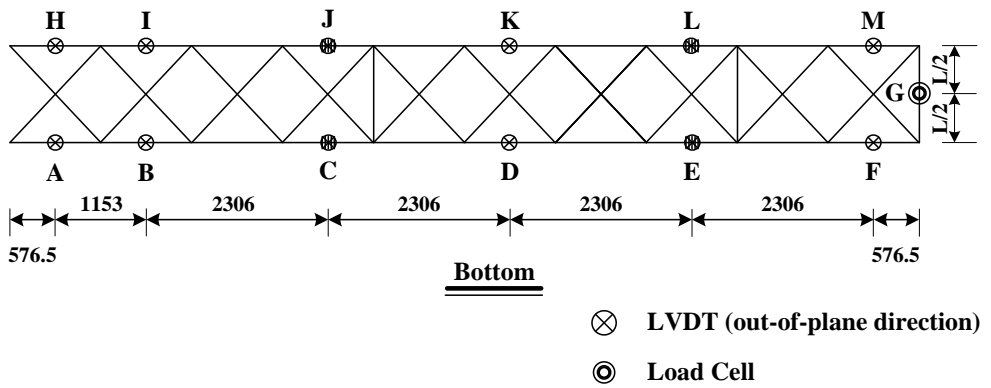

Fig. 4. Lattice girder: locations of measuring devices (units in $\mathrm{mm}$ ) 


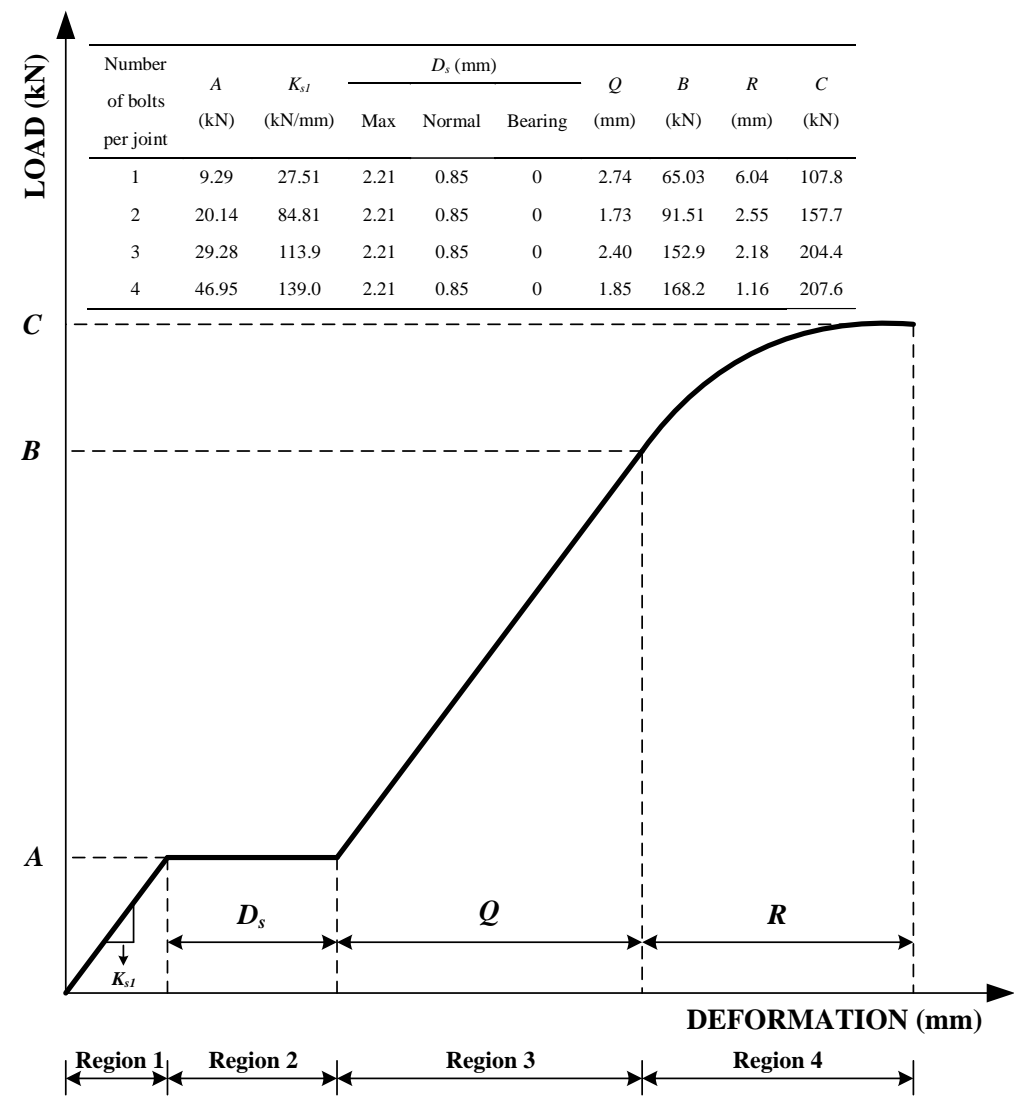

Fig. 5. Ungkurapinan's joint-slip model, based on [3, 9]

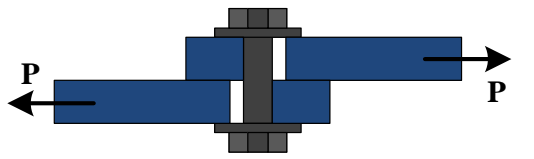

(a) Bearing

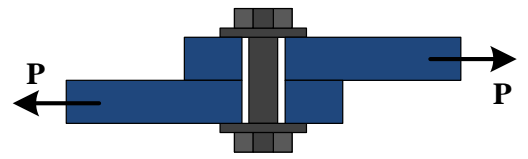

(b) Normal

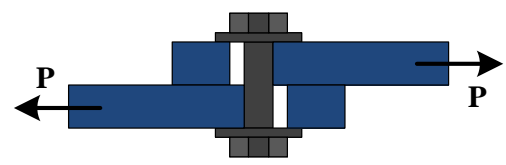

(c) Maximum

Fig. 6. Different bolt hole construction clearance configurations $(\mathrm{P}=$ load $)$ 


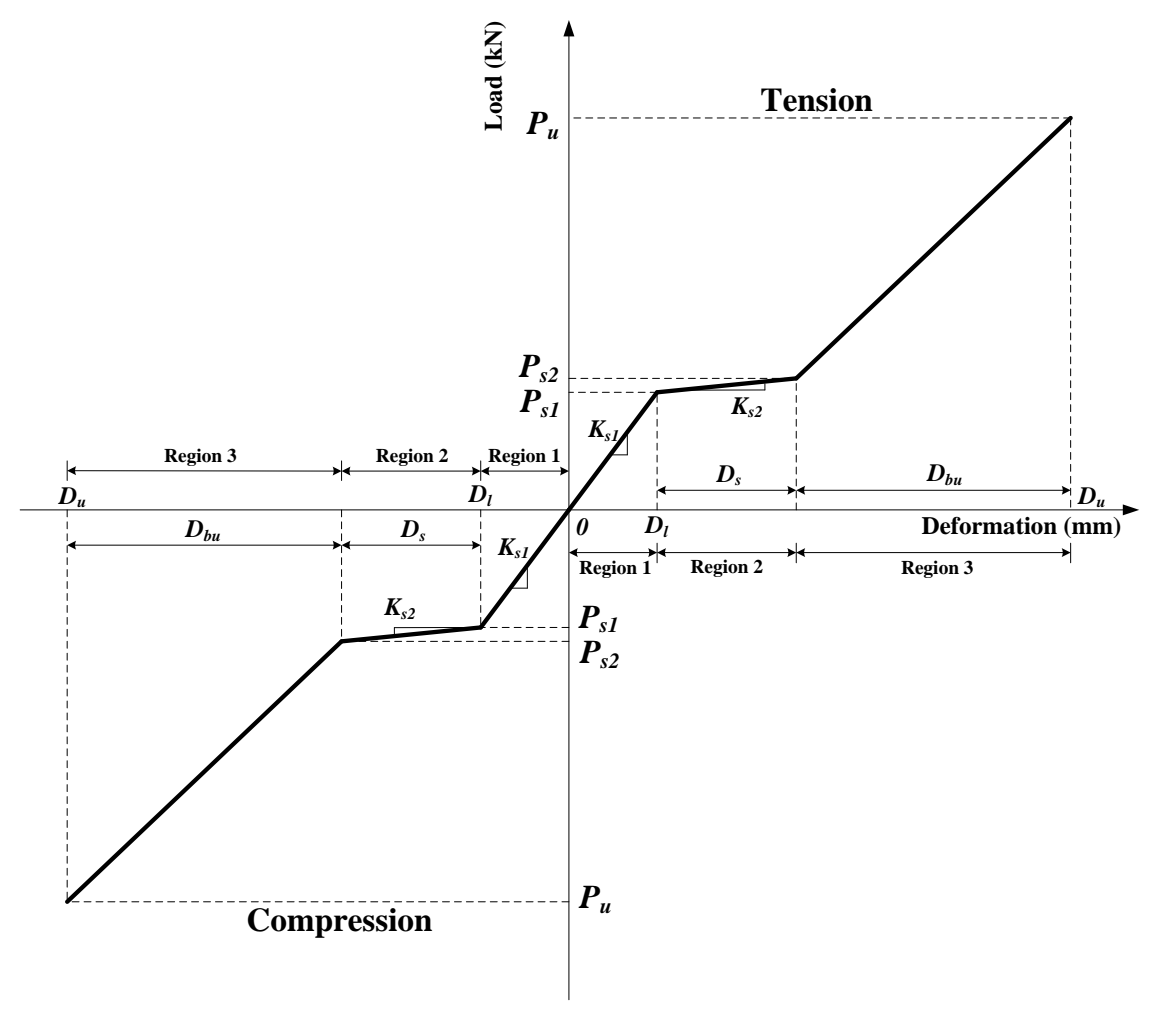

Fig. 7. Improved joint-slip model

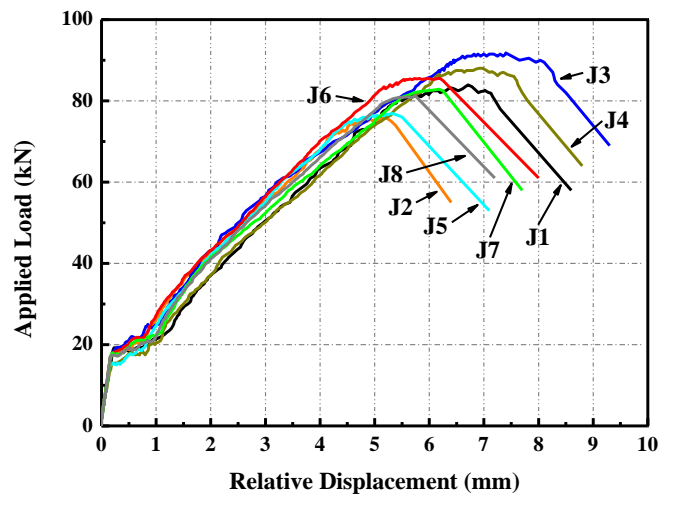

Fig. 8. Load versus relative displacement for tested connections
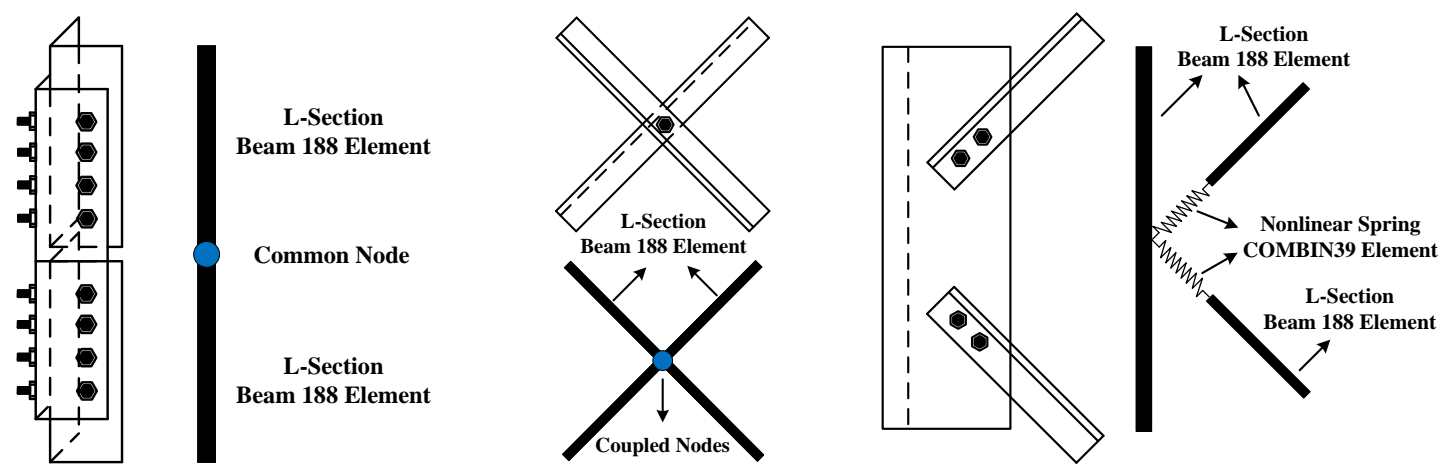

(a) Lap-splice bolted connection

(b) Intersection connection

(c) Single-leg bolted connection

Fig. 9. Bolted connection specimens and corresponding FE model representation 


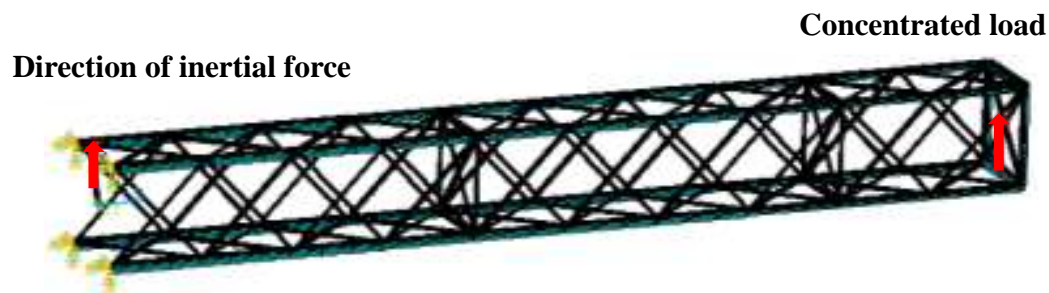

Fig. 10. FE model (Model P) of the lattice girder

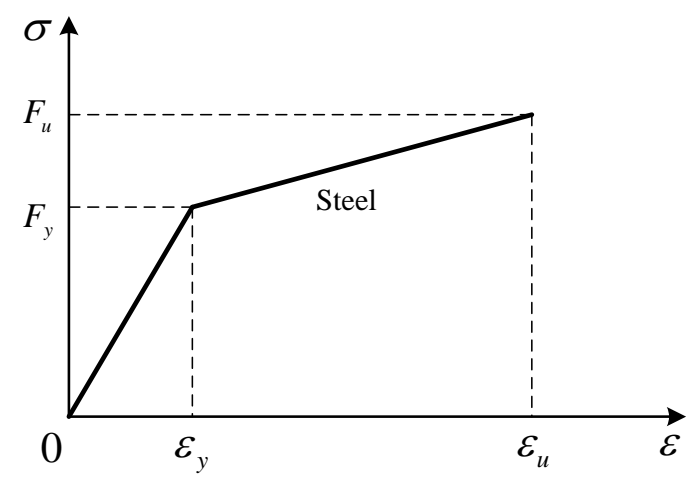

Fig. 11. Material constitutive model

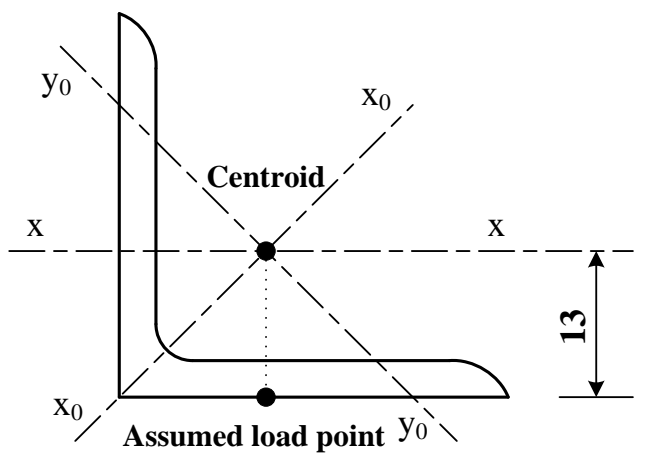

Fig. 12. Load point of web member $(\mathrm{L} 45 \times 5)$ (units given in $\mathrm{mm}$ ) 


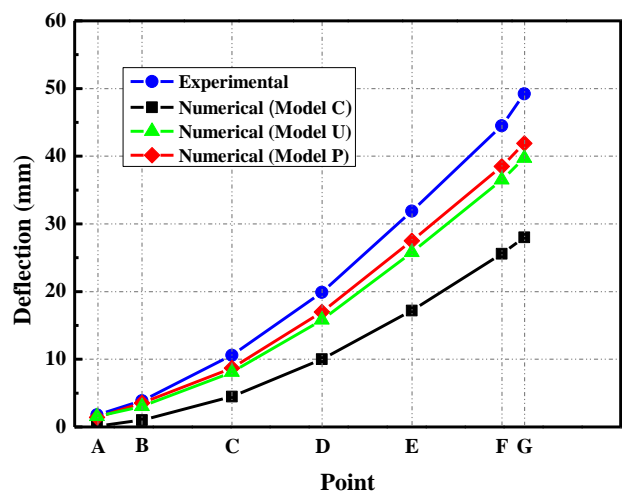

(a) $30 \%$ ultimate load

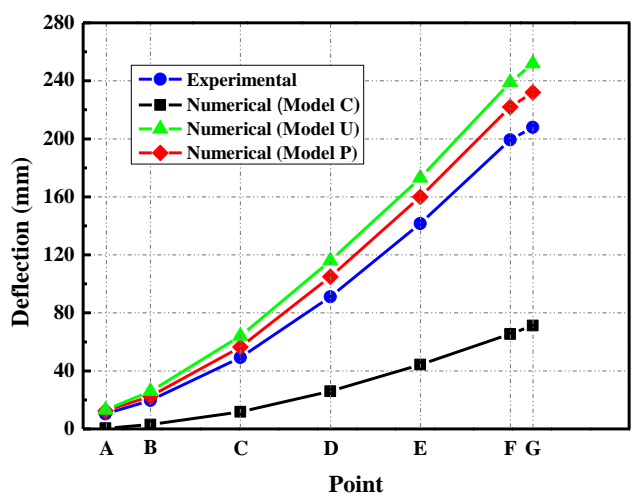

(c) $70 \%$ ultimate load

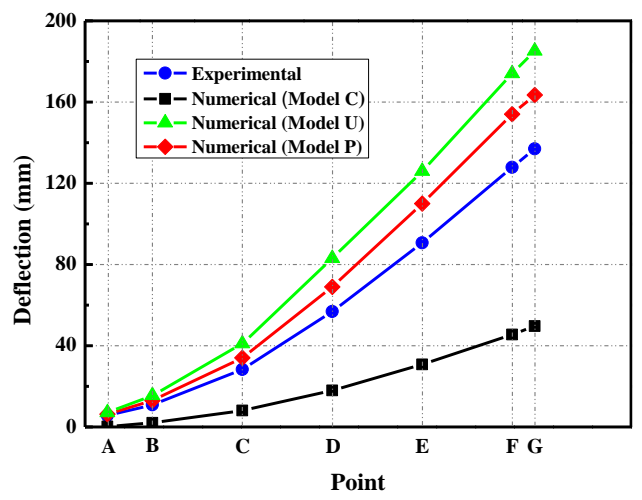

(b) $50 \%$ ultimate load

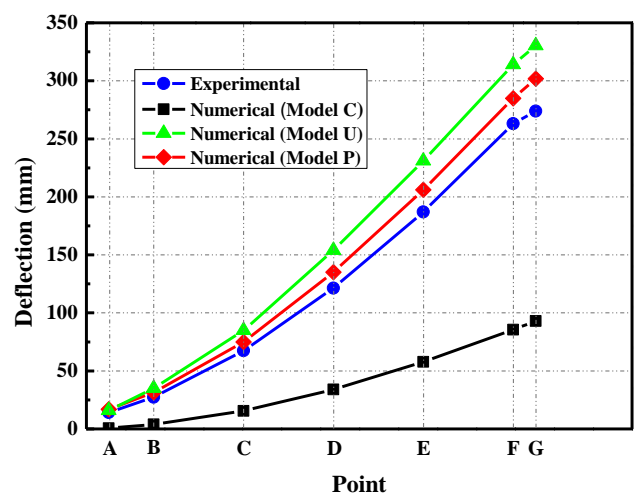

(d) $90 \%$ ultimate load

Fig. 13. Deflections of the lattice girder at different percentages of ultimate load

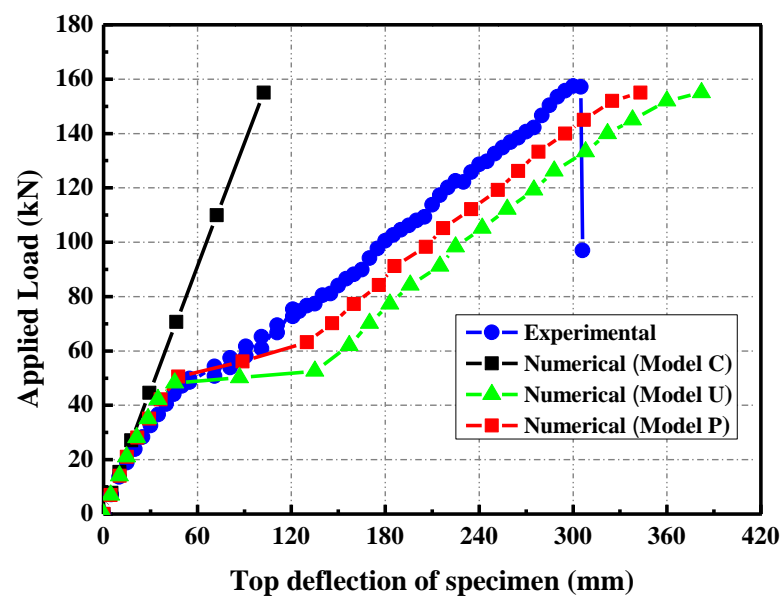

Fig. 14. Comparison of experimental and numerical results of load versus deflection on top of the lattice girder's free end 


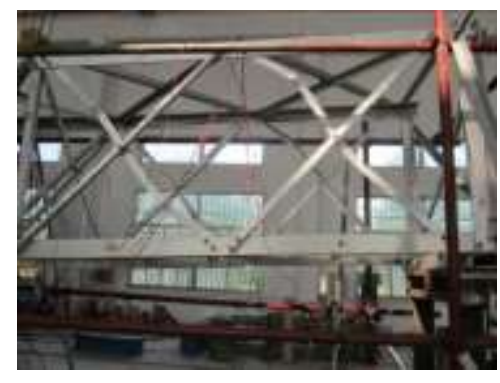

(a) Experimental failure mode

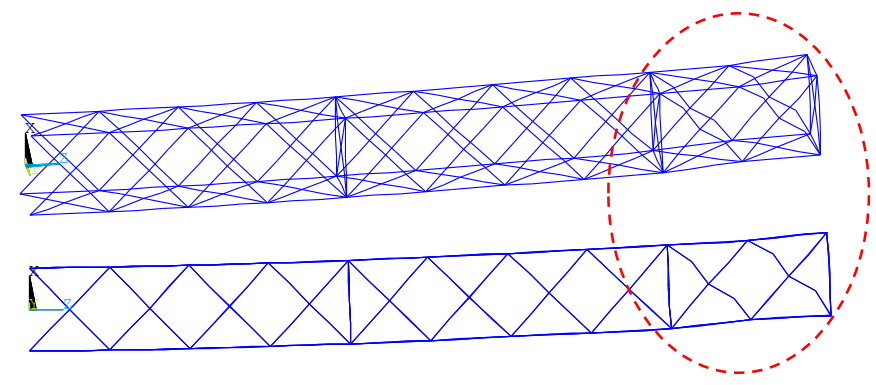

(b) Numerical failure mode

Fig. 15. Failure mode of the lattice girder 